\title{
A numerical method to predict crossflow rate resulted from downhole leaks
}

\author{
Nasser M. Al-Hajri ${ }^{1}$. Mohammed D. Al-Ajmi ${ }^{1} \cdot$ Mohamed Mahmoud $^{2}$
}

Received: 28 February 2018 / Accepted: 10 June 2018 / Published online: 14 June 2018

(c) The Author(s) 2018

\begin{abstract}
Water injection wells often develop casing leaks that result in crossflow between two formations. The crossflow can be upward or downward depending on the respective location of each formation and the gravitation hydrostatic column between the formations. Traditionally, crossflow rates are measured by running production logs (flowmeter); a process that require well intervention. Such intervention in a well with compromised downhole integrity is not preferred as it incur additional cost and exposes the oilfield operator to possible mechanical risks such as stuck tools. In this work, we present a numerical method to predict crossflow rates without such intervention. The method requires readily available input from the water injection that includes injection flow rates and pressures, in addition, to shut-in well data. The workflow developed in this study includes nodal analysis and well performance modeling. A water injection well (Well-XYZ) was selected to validate the developed workflow as a case study in this paper. Well-XYZ has an upward crossflow that resulted from a downhole leak. The numerical method starts with building a well performance model before the leak develops. The injection data (pressure and flow rates) before leak development are used for this model. Second, a well with the same physical dimensions of Well$\mathrm{XYZ}$ is imagined and modeled as a producing well from the downhole formation to the leak point. The shut-in well data of Well-XYZ are used to build the production well model. Third, we choose the leak point as the system node and obtain its pressure either by direct measurement or through calculation. Once the system node pressure is obtained, it is inputted as the wellhead producing pressure of the imagined well and its production rate will be the crossflow rate. The results of this method were tested by running a production log on Well-XYZ. The results of the production log showed that the method was able to accurately predict the crossflow rate with a less than $2 \%$ error.
\end{abstract}

Keywords Downhole leaks $\cdot$ Crossflow $\cdot$ Nodal analysis $\cdot$ Well performance $\cdot$ Water injection

\section{List of symbols \\ D Depth (ft) \\ $d \quad$ Pipe inside diameter (inch) \\ $d_{1} \quad$ Pipe diameter (inch) \\ $d_{2} \quad$ Orifice diameter (inch) \\ $f \quad$ Friction factor (dimensionless) \\ FL Fluid level}

Mohamed Mahmoud

mmahmoud@kfupm.edu.sa

Nasser M. Al-Hajri

nasser.hajri.22@aramco.com

Mohammed D. Al-Ajmi

mohammed.ajmi.11@aramco.com

Saudi Aramco, Abqaiq 31311, Saudi Arabia

2 King Fahd University of Petroleum and Minerals, Dhahran 31261, Saudi Arabia

$\begin{array}{ll}g_{\mathrm{c}} & \text { Gravity component }\left(32.2 \mathrm{ft} / \mathrm{s}^{2}\right) \\ \text { HPAL } & \text { Hydrostatic pressure above the leak } \\ \text { II } & \text { Injectivity index (bbl/day/psi) } \\ \text { IPR } & \text { Inflow performance relationship } \\ \text { LD } & \text { Leak depth } \\ \text { LIB } & \text { Lead impression block } \\ P_{1} & \text { Fluid upstream pressure (psi) } \\ P_{\text {Downhole-inj }} & \text { Bottom-hole injection pressure (psi) } \\ \text { PI } & \text { Productivity index (bbl/day/psi) } \\ P_{\mathrm{r}} & \text { Static bottom hole reservoir pressure (psi) } \\ P_{\text {system node }} & \text { Selected node to represent system model } \\ & \text { (psi) } \\ P_{\text {wf }} & \text { Flowing bottom hole pressure (psi) } \\ P_{\text {WHinj }} & \text { Wellhead injection pressure (psi) } \\ Q & \text { Volumetric flow rate (bbl/day) } \\ \Delta P_{\mathrm{f}} & \text { Frictional pressure losses (psi) } \\ \Delta P_{\mathrm{g}} & \text { Gravitational pressure losses (psi) }\end{array}$

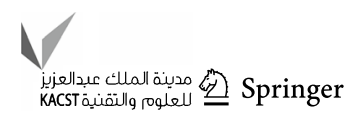




\section{$\phi \quad$ Wellbore deviation angle \\ $\rho_{\mathrm{w}} \quad$ Water density $\left(\mathrm{lb}_{\mathrm{m}} / \mathrm{ft}^{3}\right)$}

\section{Introduction}

Well integrity monitoring is an important aspect of safe well production or injection operations. Conventional well integrity monitoring mechanisms include; wellhead tree valves tests, landing base inspections, annuli surveys, temperature, and corrosion logging. When an integrity issue arises, well repair operations by means of a workover rig are typically needed to restore well integrity. Proper well integrity diagnostics (especially quantifying leak crossflow rates) is essential to the planning of crossflow isolation and the subsequent well workover. Wells under leak crossflow mode are classified as being in a well control situation. The workovers of such wells require proper knowledge of crossflow rate to design the well intervention that will lead to securing the well.

Currently, downhole leaks are quantified by running spinners (flowmeters) using wireline, coiled tubing or other conveyance methods. The direction of a crossflow is also identified by the spinners. However, such measurements may not be an operationally or economically viable option at times. Hence, accurately calculating the crossflow from surface data is a cost-effective alternative during well control situations in order to minimize well interventions.

The objectives of this paper is to develop a work flow based on numerical modeling, well performance, and nodal analysis to locate and quantify the downhole leaks and crossflow rate. The development of such workflow will eliminate the need for costly production logging that is required in such situations.

\section{Literature review}

To detect leaks, several logs are combined and interpreted such as temperature, pressure, corrosion and noise. Temperature logs detect crossflow while pressure log identifies the fluid type from its gradient. Noise logs detect fluid frequency movement while corrosion logs evaluate the condition of tubing and casing.

Temperature profiles from logs provide diagnostics to downhole problems and crossflow behind casing (Petricola and Watfa 1993). Interpretation of temperature logs for flow measurements was extensively studied (Nowak 1953; Antonio Romero-Juarez 1969; Antonio 1979).

Noise logging surveys are used in both production and injections wells (Maslennikova and Savinlov 2012). The concept relies on correlating noise amount with flow rate where high noise amplitude indicates locations where flow causes extra turbulence such as perforations or channels and leaks. McKinley provided flow rate estimation from acoustic amplitude produced by the leak flow (McKinley et al. 1973). McKinley also used noise logging to detect the downhole leaks, this can be achieved by profiling the noise amplitude at different tool frequencies (1994). Mohamed (1983) presented a time lapse technique that improved the interpretation of the spinner flowmeter logging to locate the leak points with high accuracy. Time laps method involves recording the spinner profiles at different times in the same well and comparing these surveys at different times was proven to be an effective technique to quantify and locate the small leaks. However, time lapse surveys use similar equipment as used before (diameter and spinner size). In addition, an ultrasonic leak detection logging tool was introduced to detect very small leaks and also it can be used to determine the leaks in the production tubing and outside the pipe (Julian et al. 2007a). Johns (2007b) presented an ultrasonic leak detection method to locate small leaks behind the tubing and in casing as well. This method is based on ultrasonic signature and/or an audible signature. The factors affecting ultrasonic signature are; leak path geometry, differential pressure across the leak, and leak rate. Yinghui (2016) presented a methodology to estimate flow rates for downhole leaks using linear acoustic array by correlating the source waveform with the leak flow rate rather than the amplitude.

Corrosion logs vary from mechanical caliper tools; to detect internal conditions of the pipes, electromagnetic tools; which detects the overall inside and outside thicknesses of the pipe, and ultrasonic acoustic tools; which detects the signal casing string thickness (AlGhasham et al. 2005).

\section{Well performance modeling and nodal analysis}

Well performance modeling is a consistently dependable tool in establishing well injection and/or production behavior. The principles of production engineering systems analysis were first outlined by Gilbert in the early 1950s (Takacs and Turzo 1994). Well performance modeling is particularly effective in water wells due to the single phase flow characteristic of water injectors that facilitate accurate computation of the required well dynamic parameters (Al-Hajri et al. 2015a). Recently, well performance modeling techniques were demonstrated to capture the behavior of a wastewater disposal system (Al-Hajri et al. 2015a). This modeling was later used to forecast future injection scenarios (Al-Hajri et al. 2015b).

Nodal analysis techniques are renowned in well performance modeling. Nodal Analysis is defined as the standard technique used to evaluate the performance of integrated production systems (Zhou et al. 2016). The term 'Nodal Analysis' was first introduced by Brown (1980) to calculate 
the pressure and flow rate values at any point (node) in a flow network or production system.

When performing nodal analysis, the desired well system is divided into different segments based on selected nodes from the overall system outline. The techniques of nodal analysis were heavily used to develop the proposed methodology in this paper.

\section{Case study background}

The case study of this paper, Well-XYZ, is a tubing-less water injector. Figure 1 shows the completion schematic of Well-XYZ. The well is part of an injection network that has a centralized pumping facility.

The central injection facility experienced a sudden drop in injection pressure from 2600 to 1600 psi. Upon a site survey of all flow lines and injection wells connected to the central injection facility, Well-XYZ was suspected to have a downhole leak. Well-XYZ has exhibited a low injection pressure compared to previous injection history. A downhole leak was confirmed by shutting-in Well-XYZ as the injection pressure of the central injection facility increased gradually to 2400 psi. In addition, Well-XYZ shut-in wellhead pressure was observed to be zero psi.

To investigate the downhole integrity issue, the wellbore of Well-XYZ was drifted with 6- and 3.8-in. gauge rings. Both drift sizes were not able to pass below $1374 \mathrm{ft}$ inside the 9-5/8-in. casing. Then, a 4.7-in. Lead Impression Block (LIB) was run to identify the shape of the obstruction. The

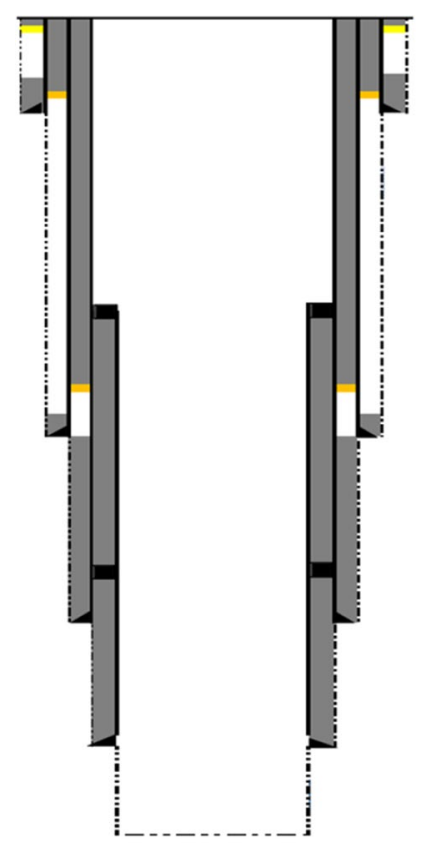

18-5/8-in. casing shoe at $975 \mathrm{ft}$

7-in. liner top at 2,058 $\mathrm{ft}$

$13-3 / 8$-in. casing shoe at $2,401 \mathrm{ft}$

9-5/8-in. casing shoe at $4,568 \mathrm{ft}$

$7 \mathrm{in.}$-liner shoe at $7,280 \mathrm{ft}$

Well total depth at $7,569 \mathrm{ft}$
LIB showed a clear side mark suggesting mechanical damage to the 9-5/8-in. casing at tagged depth (1374 ft). Figure 2 shows the LIB run in Well-XYZ.

Based on the above diagnostics, a downhole leak resulting from a mechanical damage to the 9-5/8-in. casing was confirmed. The depth of the leak was determined to be $1374 \mathrm{ft}$. An active upward crossflow between the deep injection formation (high pressure) and the shallow leak formation (low pressure) was confirmed as well. Quantifying the casing leak crossflow in Well-XYZ was necessary to design well control and remedial workover actions.

\section{Crossflow calculation methodology}

A continuous surface injection data (pressure and injection rate at the surface) before leak development in addition to the shut-in data were used in this study to quantify the casing leak crossflow. Nodal analysis and well performance modeling techniques were used to perform the computations associated with the proposed method. The crossflow leak calculation workflow is summarized as follows.

\section{Generating well-XYZ performance model using pre-leak injection data}

A base model for Well-XYZ's IPR was generated using continuous injection data prior to leak development. The IPR quantifies the fluid flow into the reservoir as dictated by three parameters:

1. Injectivity index (II) is defined as the ratio between an injection flow rate and a difference between a downhole injection pressure and a static bottomhole reservoir pressure. The unit for the injectivity index is $\mathrm{B} / \mathrm{D} / \mathrm{psi}$.

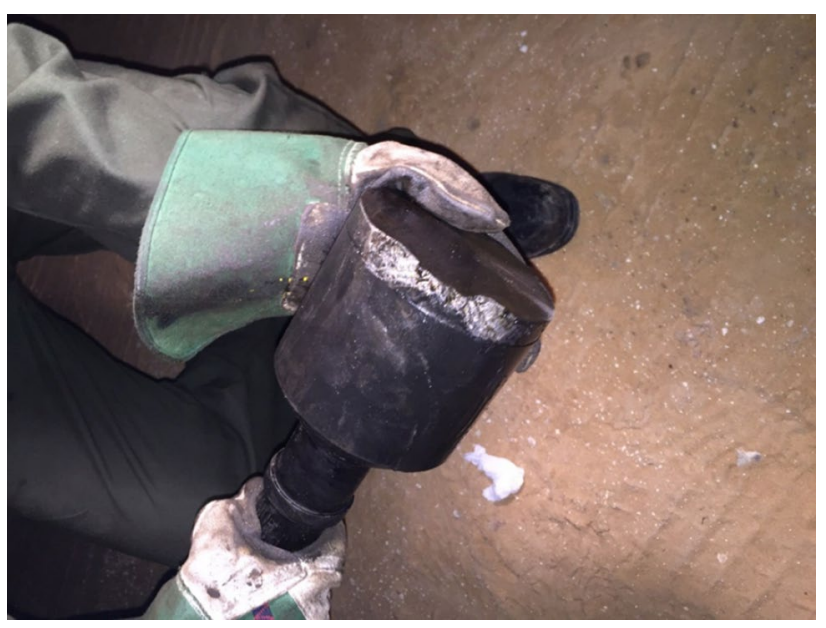

Fig. 2 A Picture of the LIB run in Well-XYZ showing a clear side mark

Fig. 1 Well XYZ completion schematic 
2. Static bottomhole reservoir pressure $\left(P_{\mathrm{r}}\right)$ represents a measurement of a well's bottomhole reservoir pressure at shut-in condition. The measurement is taken after a pre-defined period to allow the well pressure to stabilize. The unit for the static bottomhole reservoir pressure is psi.

3. Downhole injection pressure $\left(P_{\text {downhole-inj. }}\right)$ is defined as the downhole flowing pressure corresponding to a wellhead injection pressure at a given rate. The unit for the downhole injection pressure is psi.

When the above three parameters are known, the IPR for an injection well can be obtained using Eq. 1:

$Q=\mathrm{II}\left(P_{\text {downhole }_{\text {inj }}}-P_{\mathrm{r}}\right)$,

where $Q$ is the injection rate, II is the injectivity index, $P_{\text {downhole-inj }}$ is the downhole injection pressure, and $P_{\mathrm{r}}$ is the reservoir pressure. The II for Well-XYZ was obtained from the most recent pressure transient analysis (fall-off test) while, the $P_{\mathrm{r}}$ was obtained from a recent wireline measurement. As for Well-XYZ $P_{\text {downhole-inj, }}$ the wellhead injection pressures were converted to bottom-hole injection pressures at different rates. The injection flow rate data are obtained from a surface flowmeter. The flowmeter uses differential pressure measurements across an orifice plate installed in the injection line via pressure sensors as explained in Fig. 3 to compute the flow rate.

Based on the inputs provided from the pressure sensors $\left(P_{1}\right.$ and $P_{2}$ ) and other input parameters, the surface injection flow rate is calculated using Eq. 2.

$Q=\frac{22800 d_{2}^{2}}{\sqrt{1-\left(\frac{d_{2}}{d_{1}}\right)^{4}}} \sqrt{\frac{\left(P_{1}-P_{2}\right)}{\rho_{\mathrm{w}}}}$, where $d_{1}$ is the pipe diameter, $d_{2}$ is the orifice diameter, $P_{1}$ is the upstream pressure, $P_{2}$ is the downstream pressure, $\rho_{\mathrm{w}}$ is the water density. The most recent flowmeter measurements from Well-XYZ that are used for modeling are shown in Fig. 4.

The wellhead injection pressures were converted to downhole pressures using Eq. 3.

$P_{\text {Downhole }_{\mathrm{inj}}}=P_{\mathrm{WH}_{\mathrm{inj}}}+\frac{\rho_{\mathrm{w}} \sin \phi D}{144}-\left[\frac{f \rho_{\mathrm{w}} Q^{2}}{14.79 g_{\mathrm{c}} d^{5}}\right]$.

The above conversion from $P_{\text {WHinj }}$ to $P_{\text {Downholeinj }}$ was made using a commercial software for computational ease. Equation 1 is then used to generate the IPR curve, which shows the relationship between the bottom-hole injection pressure and injection rate for Well-XYZ.

The base IPR model for Well-XYZ was tested using the wellhead as a system node. The water flow rates corresponding to wellhead injection pressures generated from the IPR base model are compared to the measured injection data (actual surface flowmeter data). However, IPR base model results and surface flowmeter data often do not match. This attributed to the need for calibration of IPR base models. The reason for needing IPR model calibration, is the unavailability of an injectivity index value that corresponds to the same time of recording the flowmeter injection data.

Calibration of the base IPR model is performed by regressing on the injectivity index. The curves are generated using the wellhead as the system node. The injection water flow rates obtained from the generated curves are compared to actual flow data until the error between the actual and simulated data is minimized. Figure 5 below shows Well-XYZ calibrated injection model with an injectivity index of $31 \mathrm{~B} / \mathrm{D} / \mathrm{psi}$. Since the outflow performance relationship (OPR) of Well-XYZ under injection condition is not part of the methodology proposed in this paper, it was excluded from the base model. However, the OPR

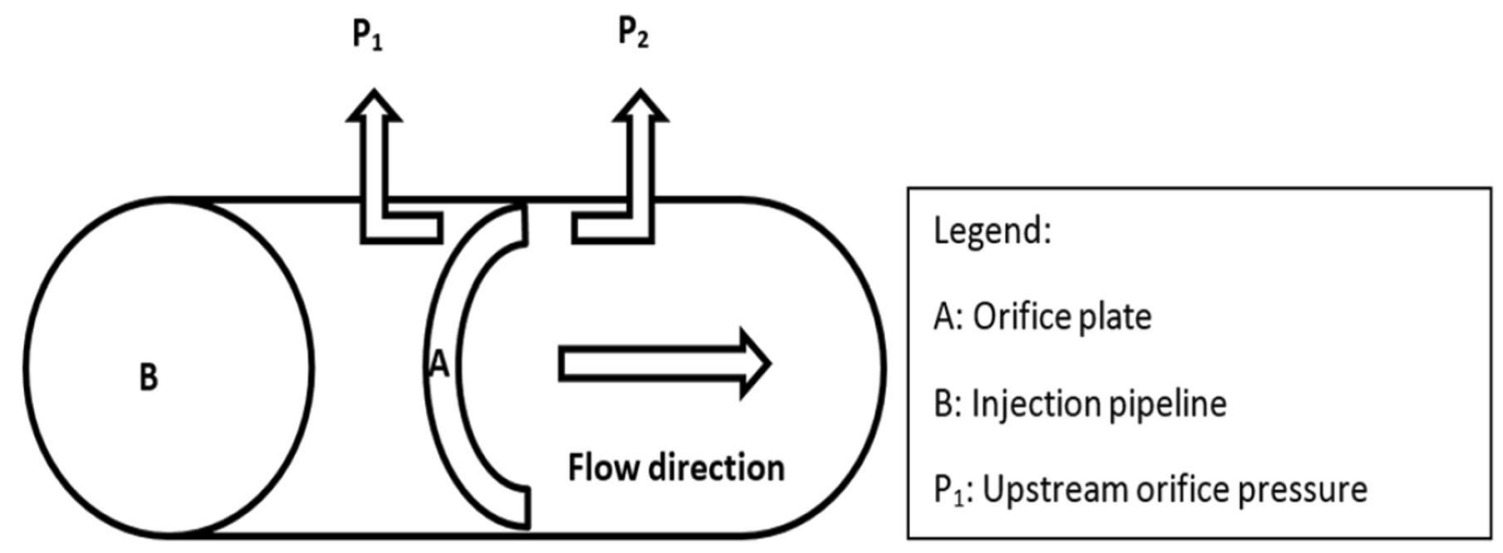

Fig. 3 Orifice plate flow rate measurements set-up 
Fig. 4 Well-XYZ injection data used to build the base well performance model
Fig. 5 Calibrated inflow performance relationship of well-xyz
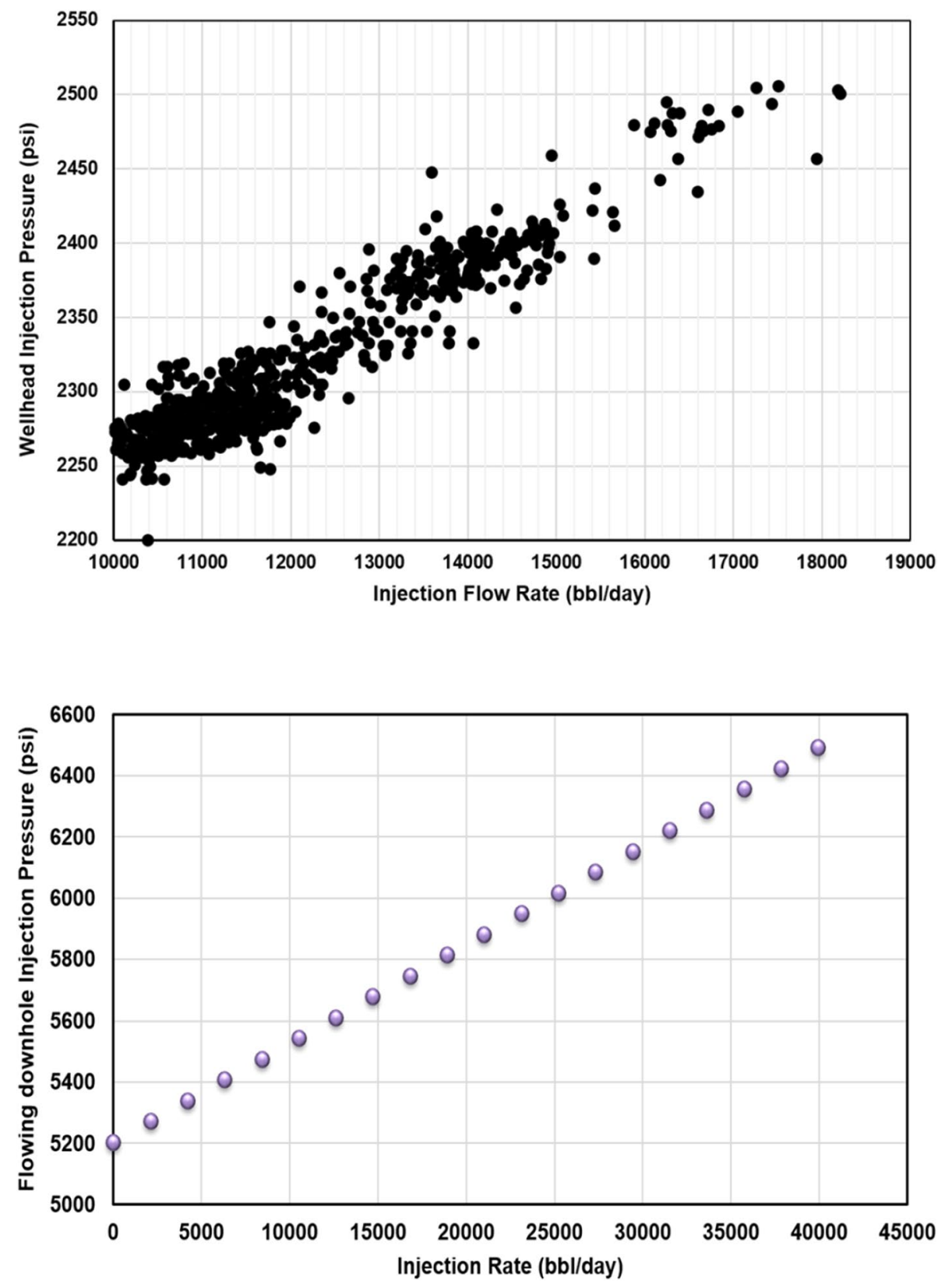

will be generated under crossflow condition as part of the next section.

\section{Generating an imaginary water production well model}

An imaginary production well mimicking the flow characteristics and properties of Well-XYZ is envisioned. Figure 6 compares the schematic of Well-XYZ with the imaginary production well. The objective from conceiving this imaginary production well is to simulate Well-XYZ leak crossflow at shut-in condition. The imaginary production well has the following characteristics:
1. The system node (or wellhead) of the imaginary well is set to be at the leak depth of Well-XYZ.

2. The imaginary production well has the same reservoir pressure of Well-XYZ.

3. The productivity index of the imaginary production well is assumed equal to the injectivity index of Well-XYZ since both wells have the same reservoir rock matrix and fluid properties.

4. The imaginary production well is undergoing an assumed steady state flow regime. The same assumption is made for Well-XYZ at normal injection conditions. 
Fig. 6 Comparison between Well-XYZ and imaginary production well schematics

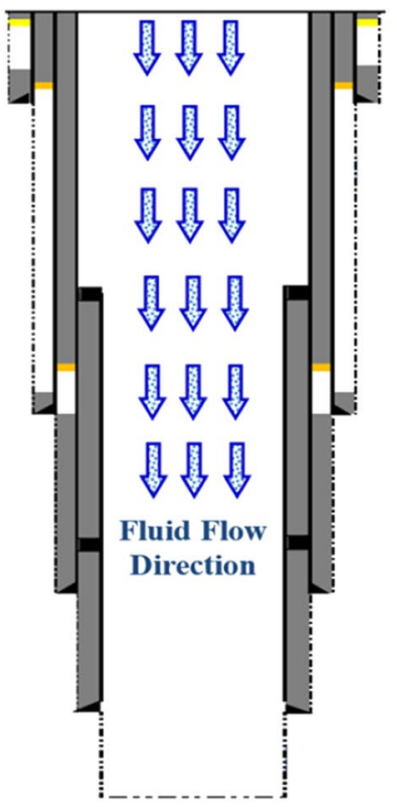

Well-XYZ at

Normal Injection Condition
It is important to note that the productivity index of the imaginary production well (third characteristic) will generate the minimum expected flow rate with negligible variations from actual rate. The productivity index of the imaginary production well is expected to increase from the assumed value which is the injectivity index of Well-XYZ. This is due to possible skin factor improvement when the imaginary production well is back-flowed, as is the case with the leak crossflow. In such scenario, the reservoir rock pore throats are cleared from plugging material which is field proven in most water injectors when back-flowed. El-Hadidi et al. (1981) stated a $10 \%$ increase of the injectivity index due to skin improvement when water injectors are back-flowed (El-Hadidi et al. 1981). However, quantifying the productivity index improvement resulting from back-flowing water injectors is not part of the scope of this paper.

The system node of the imaginary production well is not the conventional node when modeling water wells, where the wellhead is usually the system node. The reason behind shifting the node deeper to the leak depth is to exactly simulate the existing crossflow of Well-XYZ which is taking place between two formations.

To accurately model the crossflow rate of Well-XYZ, both the IPR and OPR need to be generated. The crossflow rate of Well-XYZ will be the operating point (intersection) of the two curves at the selected system node pressure. The IPR of the imaginary production model is generated using Eq. 4 .

$Q=\operatorname{PI}\left(P_{\mathrm{r}}-P_{\mathrm{wf}}\right)$.

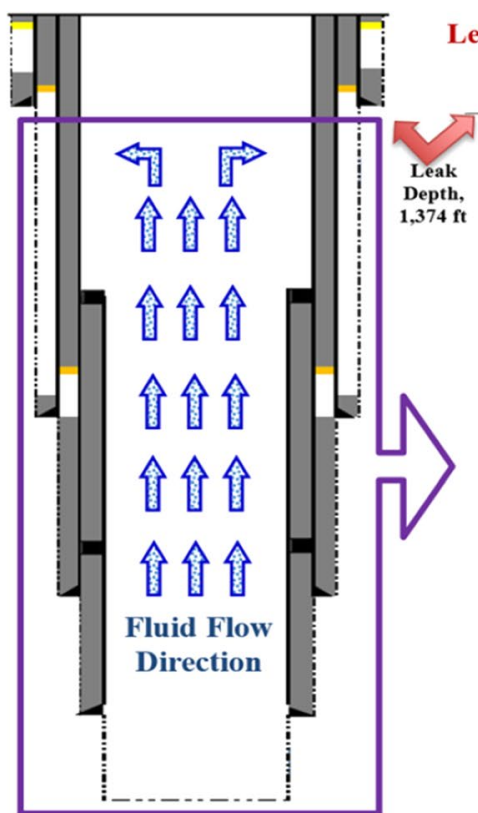

Well-XYZ at

Crossflow Condition
Leak Depth is the System Node of the Imaginary Well

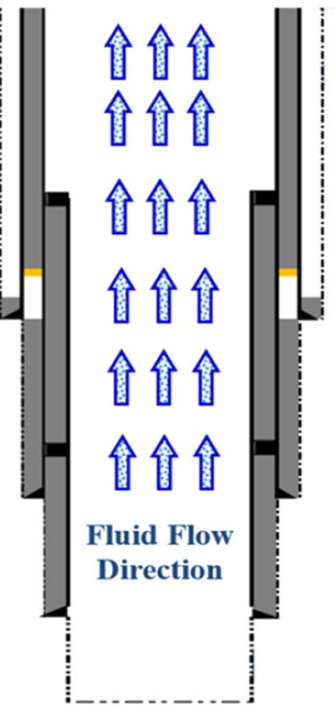

Imaginary Well at

Normal Production Condition
The imaginary production well IPR model can be generated since the PI and $P_{\mathrm{r}}$ values are known. The PI was defined as the II of Well-XYZ and the same value of $P_{\mathrm{r}}$ is used for Well-XYZ and the imaginary production model. Several values of the $P_{\mathrm{wf}}$ can be assumed to obtain the corresponding production rate. The $P_{\mathrm{wf}}$ is defined as the bottomhole flowing pressure of the imaginary well at producing conditions.

The OPR curve for the imaginary production well was generated using Eq. 3. However, to distinguish between the two equations, different terminologies were defined while keeping the equation parameters as it is. In addition, a change of sign in the frictional pressure loss term was made to factor in the direction of the flow as the imaginary well is presumed producing. Equation 5 represents the OPR for the imaginary production well.

$P_{\mathrm{wf}}=P_{\text {system node }}+\frac{\rho_{\mathrm{w}} \sin \phi D}{144}+\left[\frac{f \rho_{\mathrm{w}} Q^{2}}{14.79 g_{\mathrm{c}} d^{5}}\right]$.

The $P_{\text {System Node }}$ was defined earlier in the characteristic of the imaginary production well as the leak depth. To generate the OPR, a system node pressure is selected. At each system node pressure, several $P_{\text {wf }}$ values are assumed and the corresponding flow rates $(Q)$ are calculated. The opposite can be performed as well which is assuming different flow rates and calculating the corresponding $P_{\mathrm{wf}}$. The relationship between $P_{\mathrm{wf}}$ and $Q$ at each system node represent a standalone OPR curve. Figure 7 shows the IPR/OPR curve of the imaginary production model at different system node values. 


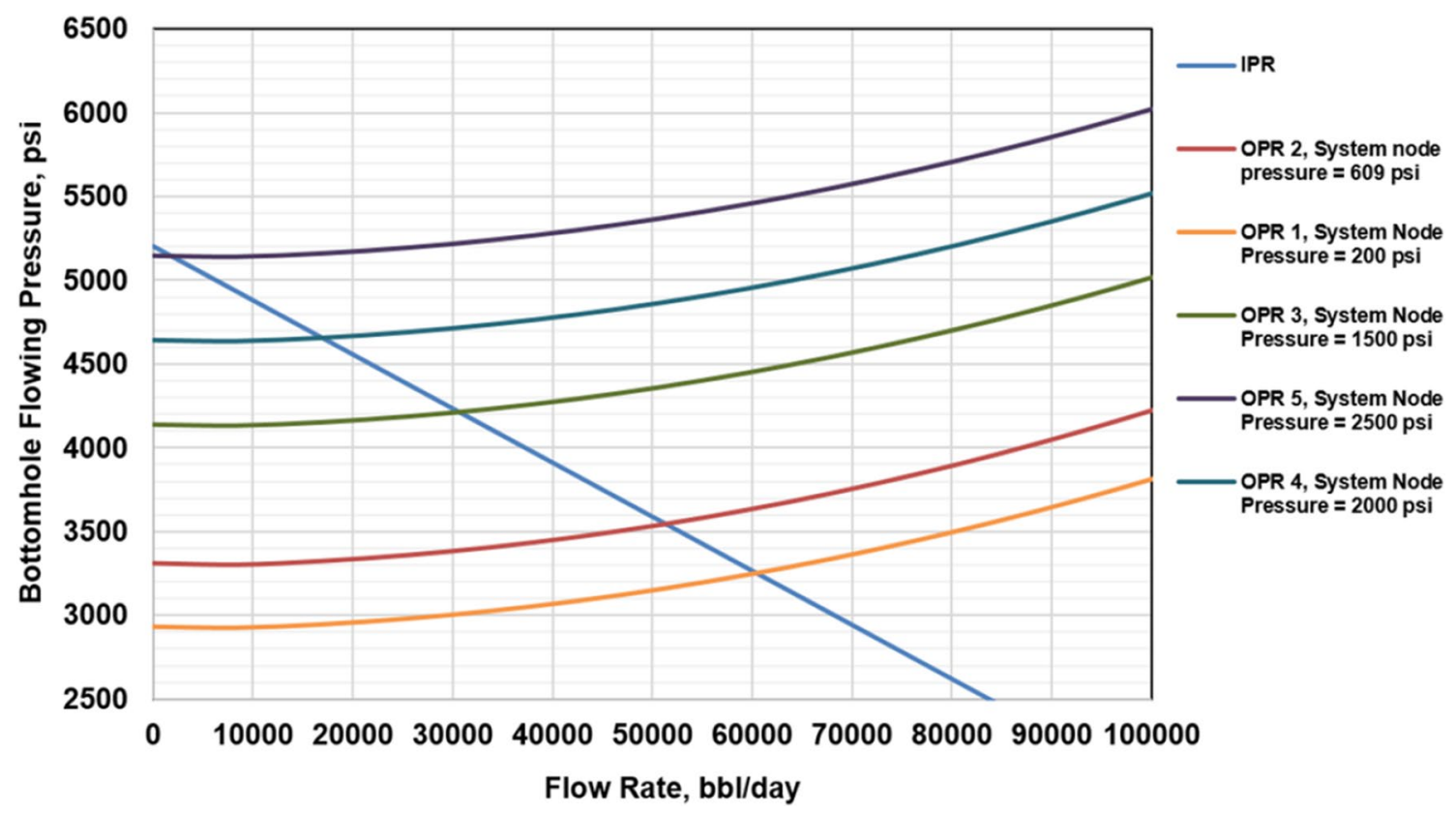

Fig. 7 The IPR/OPR curve of the imaginary production model at different system node values

\section{Calculating the system node pressure of the imaginary production well}

The last step of calculating the crossflow in Well-XYZ, is to determine the flowing pressure across the leak zone which was selected as the system node. When the system node pressure is obtained (either by measurement or calculation), the casing leak crossflow rate is determined as the intersection of the IPR/OPR curve (Fig. 7) at the corresponding system node pressure.

Well-XYZ was identified with a zero wellhead pressure when the leak took place. The leak zone depth was determined to be at $1374 \mathrm{ft}$ from the gauge ring tag and LIB run and Well-XYZ water level (vacuum depth or extent) was determined to be at $20 \mathrm{ft}$ from the weight change observed when running the gauge ring survey.

The flowing system node pressure across the leak zone can be computed by the knowledge of fluid level following Bernoulli energy balance equation. The stagnation pressure, as described by Bernoulli's principle, is the static pressure at a stagnation point in a fluid flow. At a constant entropy, the velocity OF the fluid is zero and the kinetic energy is converted into pressure energy which makes stagnation pressure equals to the sum of dynamic pressure (Clancy 1975). In this case, the stagnation point is the leak depth and the stagnation pressure is the pressure exerted by the water level on the leak zone while the sum of the dynamic pressure is the system node flowing pressure across the leak zone.

Accordingly, the flowing pressure across the leak depth will equal the hydrostatic pressure exerted by the fluid above the leak. The hydrostatic pressure above the leak was calculated using Eq. 6.

$\mathrm{HPAL}=(\mathrm{LD}-\mathrm{FL}) \mathrm{WG}=(1374-20)(0.45)=609$ psi.

The flowing system node pressure value of 609 psi was used as input in the imaginary well IPR model to calculate the crossflow rate. The flow rate corresponding to a system node flowing pressure of 609 psi at the leak zone was found to be 51,446 barrels per day. As such, this value is regarded as the casing leak crossflow rate of Well-XYZ.

\section{Validation of model prediction with flowmeter measurement}

To evaluate the accuracy of the developed model, the crossflow rate obtained from the calculation methodology proposed in this work was compared to an electric-line conveyed flowmeter (spinner) survey conducted during workover operation. The results of the flowmeter survey are shown in Fig. 8. The flowmeter survey indicated that a leak was present at the depth of $1380 \mathrm{ft}$. The magnitude of the leak was quantified to be 50,753 barrels per day. This represent an absolute error difference of $1.37 \%$ between the calculated and measured flow rates. The developed workflow in this study will save the use of expensive production logging to quantify the downhole leaks. 


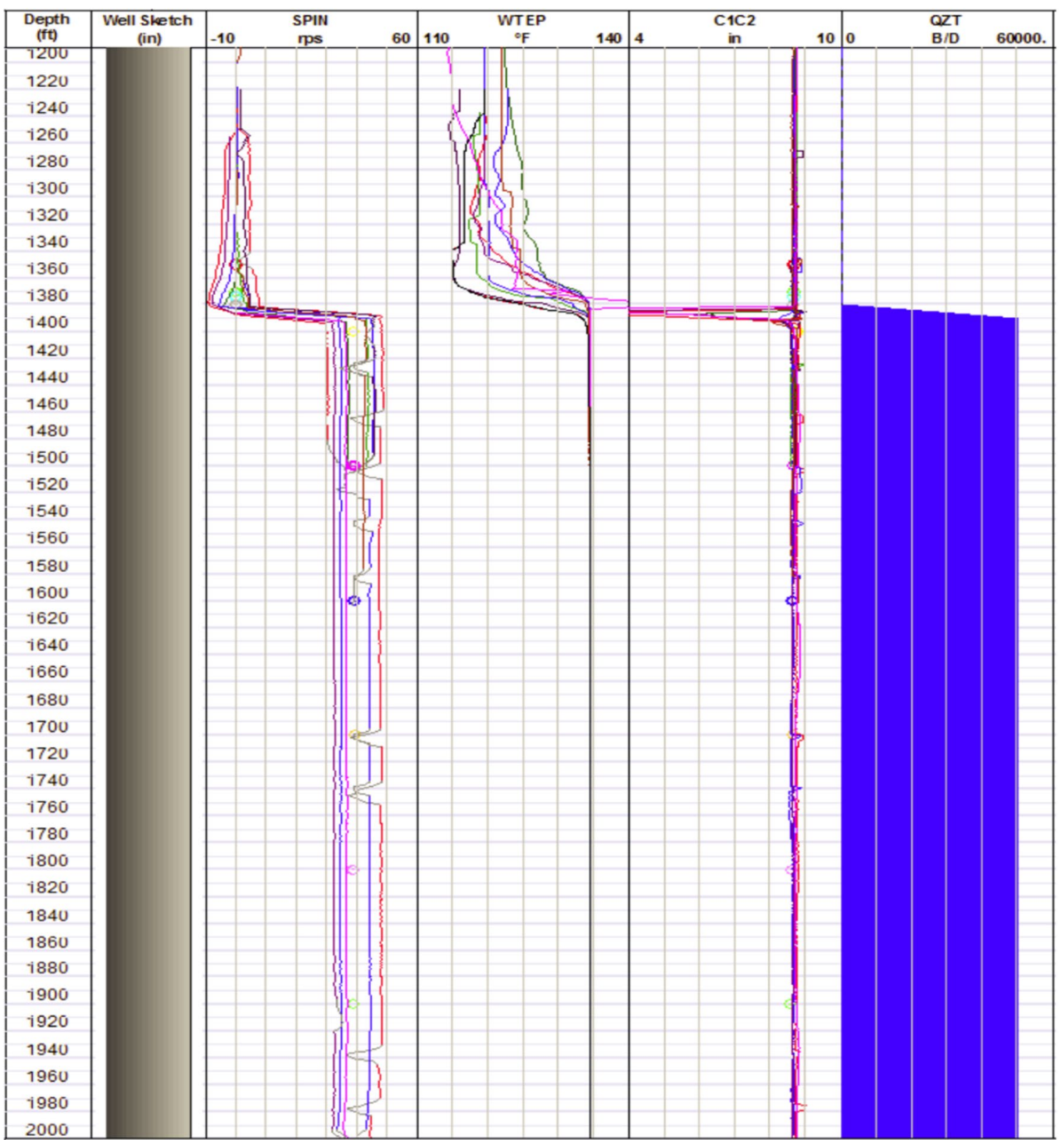

Fig. 8 The results of the flowmeter survey of Well-XYZ

\section{Error analysis}

The resulting error between model prediction and actual measurements is small. The main source of error was the variation between leak depth obtained from the gauge ring survey and the one used to calculate the system node pressure. As shown in the flowmeter survey (Fig. 8), the leak depth was found to be $1380 \mathrm{ft}$ ( $6 \mathrm{ft}$ deeper than the value used in Eq. 6).

\section{Conclusions}

A numerical methodology was developed to calculate the crossflow rate resulting from a casing leak. The methodology depends on nodal analysis and hydraulic simulation techniques. The proposed method was found fairly accurate compared to measured values. A robust workflow with an acceptable error was developed to quantify the 
downhole casing leaks that will eliminate the need for running expensive production logging jobs.

Acknowledgements The authors would like to thank Mohamed ElNekhily for his assistance in the development of illustrations and figures.

Open Access This article is distributed under the terms of the Creative Commons Attribution 4.0 International License (http://creativeco mmons.org/licenses/by/4.0/), which permits unrestricted use, distribution, and reproduction in any medium, provided you give appropriate credit to the original author(s) and the source, provide a link to the Creative Commons license, and indicate if changes were made.

\section{References}

Al Ghasham YY, Catte DR, AlHaji AA (2005) Integrated analysis of downhole corrosion logs to investigate casing leaks. Middle east oil and gas show and conference in Bahrain, SPE 93184

Al-Hajri NM, Al-Ajmi MD, Al-Subaie FM (2015a) Full system analysis to predict the reliability of a wastewater disposal system; a hydraulic simulation-based approach. Soc Pet Eng. https://doi. org/10.2118/174348-MS

Al-Hajri NM, AlAjmi MD, Al-Subaie FM, Al-Zaharani RM, AlBenSaad ZR (2015b) Forecasting the reliability of a wastewater disposal system and predicting future corrective actions using hydraulic simulation. Soc Pet Eng. https://doi.org/10.2118/17748 8-MS

Antonio R-J (1969) A note on the theory of temperature logging. SPE paper 2464-PA. https://doi.org/10.2118/2464-PA

Antonio R-J (1979) A simplified method for calculating temperature changes in deep wells. SPE paper 7197-PA. https://doi. org/10.2118/7197-PA

Brown KE (1980) The technology of artificial lift. Petroleum Publishing Co., Tulsa

Clancy LJ (1975) Aerodynamics Chapt. 3. Wiley, New York

El-Hadidi SM, Al-Rubaie JS, Allam M et al (1981) Performance of powered water injectors in Arab ' $D$ ' reservoir of Umm Shaif field offshore Abu Dhabi. Presented at the middle east technical conference and exhibition, Manama, Bahrain, 09-12 March. SPE9631-MS. https://doi.org/10.2118/9631-MS

Julian K, Cismoski Y, Borwin R (2007a) Downhole leak determination using fiber optic distributed temperature surveys at Prudhoe Bay, Alaska. SPE 107070, California

Julian K, Johns S, Robertson DB (2007b) Detection ultra-small leaks with ultrasonic leak detection-case histories from the North Slope, Alaska. SPE paper 108906 presented at 2007 international oil conference and exhibition, 27-30 June 2007, Mexico

Lu Y, Walters D, Hill F (2016) Flow rate estimation of downhole leaks using acousting sensor array. SPE paper 181455 presented at ATCE Dubai, UAE, Sep., 2016

Maslennikova YS, Savinlov AV (2012) Spectral noise log data processing technologies. SPE paper 162081 presented at Russian oil and gas exploration and production conference and exhibition, October 2012

McKinley R (1994) Temperature radioactive tracer, and noise logging for well integrity. Robert S. Environmental Research Laboratory, Oklahoma

McKinley RM, Bower FM, Rumble RC (1973) The structure and interpretation of noise from flow behind cemented casing. J Pet Technol 25(3):329-338. https://doi.org/10.2118/3999-PA

Mohamed SK (1983) Leak detection using time-lapse technique and website computer processing. SPE paper 11450, March, 1983

Nowak TJ (1953) The estimation of water injection profiles from temperature surveys. SPE paper 953203-G, August, 1953. https://doi. org/10.2118/953203-G

Petricola FJ, Watfa M (1993) Multiwell application of downhole temperature profiles for crossflow analysis. SPE paper 25630, presented at the SPE MEOS Bahrain, April, 1993

Takacs G, Turzo Z (1994) Nodal systems analysis using objectoriented programming techniques. Soc Pet Eng. https://doi. org/10.2118/26250-PA

Zhou W, Banerjee R, Proano E (2016) Nodal analysis for unconventional reservoirs-principles and application. Soc Pet Eng. https ://doi.org/10.2118/171768-PA

Publisher's Note Springer Nature remains neutral with regard to jurisdictional claims in published maps and institutional affiliations. 